\title{
REINFORCED CONCRETE ELEMENTS SUBJECTED TO FIRE
}

\section{ATTACK}

\author{
D. Reshmasri ${ }^{1}$, B. Dheera Lessa ${ }^{2}$, N. Murali Krishna ${ }^{3}$ \\ ${ }^{1}$ Post Graduate Student, Department of Civil Engineering, Osmania University, Telangana, Hyderabad \\ ${ }^{2}$ Under Graduate Student, Department of Civil Engineering, Osmania University, Hyderabad \\ ${ }^{3}$ Professor, Department of Civil Engineering, Osmania University, Hyderabad
}

\begin{abstract}
In these days of rapid urbanization the frequency of accidents due to fire are high. Structural sustenance thereafter is always doubtful. Non availability of technical literature on concrete behavior at elevated temperatures is the reason for this shortcoming. Even if such information is available, it is too inadequate to predict the longevity of the structure and its utility for occupation. In this backdrop the present study using FEM approach is taken up to evaluate the extent of damage due to fire attack making use of MSC Nastran. The accidents due to fire are more frequently caused by electric short circuiting in the control panel rooms in high raised buildings. The damage caused to column elements is often considered more critical as the columns are the principal load carrying members transferring loads from the superstructure to footings. In the present study heat propagation in a portion of a column member subjected to heat of $1000^{\circ} \mathrm{C}$ acting for duration of two hours is evaluated using MSC Nastran. The temperature variation across the thickness of concrete is studied considering the variation of thermal conductivity with temperature and porosity. The propagation of heat and the corresponding distress to concrete is determined from surface to the central core of the column along the shorter dimension. The output results obtained from the transient thermal analysis module of Nastran are fed as inputs to the structural analysis module to obtain the stresses and strains caused by fire. A large data of such information with varying parameters of temperature, duration of fire attack and concrete properties is proposed to be generated to be used later as set of training patterns to train a BOPN based neural net paradigm. The information from the neural net output would be used for working out the sizes of equivalent structural elements in the distressed structure. The revised structural configuration with the distressed RC element replaced by equivalent elements should facilitate the structural assessment.
\end{abstract}

Keywords: Temperature, Thermal Stress, Thermal Strain, Thermal Conductivity, Porosity, Neural Network -****.

\section{INTRODUCTION}

The huge amount of expenditure incurred in the construction activity and the need to protect the life and property in the event of calamities needs to be addressed in total in the present day environment. Calamities of any kind causes distress to high rise buildings, raising doubts about their structural sustenance thereafter. It's the primary responsibility of the structural engineer to restore confidence in the minds of general public regarding the longevity of the structure. In the present study the calamity due to fire mishap has been taken up.

Even though as on date a large number of studies pertaining to fire attacks on RC buildings are available, the information available is either inadequate or inconsistent to effectively use in structural assessment. In the present study, the FEM approach making use of MSC Nastran package is used to evaluate the structural distress in concrete subjected to fire. Fire accidents occur more frequently due to electric short circuiting in high rise buildings. The damage detection caused due to sustained fire attack on a portion of the building structure is investigated. The electric panel boards from where the short circuiting happens is the source from where the fire gets emanated in tall buildings, generally go unnoticed until it assumes larger proportions. As the electric panel boards are located in the lower floors in the buildings maximum distress is expected there which is considered critical for the structural stability of the building. The inaccessibility of the origin of fire during fire attack further compounds the gravity of the situation, making rational assessment of damage impossible. The sustainability assessment of structure is considered most desirable, but there are no known methods to evaluate the extent of damage due to fire as on date. The frame members, located nearer to panel boards are more vulnerable to severe damage, posing threat to the integrity of the structure. Since the columns are the primary load carrying members transferring the load of the structure to the ground, any damage to the columns is considered a disaster.

In the present study, a concrete column with sectional dimensions $500 \mathrm{~mm} \times 300 \mathrm{~mm}$ is considered subjected to fire on one of its larger faces. The propagation of heat and the resultant damages to the concrete is evaluated till the central core of the column using the finite element package MSC Nastran. On this larger surface, only the central $200 \mathrm{~mm} \times 200 \mathrm{~mm}$ square portion is subjected to fire attack. The elevated temperature in this portion was considered $1000^{\circ} \mathrm{C}$ lasting for two hours. The propagation of heat within the square portion of $500 \mathrm{~mm} \times 500 \mathrm{~mm}$ around heated portion to a depth of $150 \mathrm{~mm}$ alone is studied using the FEM package. Temperature all around the heated square portion 
was assumed as $27^{\circ} \mathrm{C}$, the room temperature. In the analysis, the temperature variation across the depth is studied considering the variation of thermal conductivity with respect to temperature and porosity.

Having completed the thermal analysis, the temperatures obtained at different locations from the output is given as thermal inputs to find out thermal stresses and strains generated in the concrete, again making use of the same package. With known values of thermal stresses and strains, evaluated as described above, the extent of additional stresses that develop in the column member after fire attack are evaluated. It is proposed to study the extent of damage due to C-S-H (Calcium Silicate Hydrate) gel failure as well. Due to the above two reasons, on one hand the strength of concrete gets decreased and on the other the resultant stress gets increased due to the thermal stress. This may prove grave for the sustenance of the structure. Making use of the present study, a rational assessment to work out the residual strength of the structure is possible.

The structural assessment after the fire attack is proposed to be carried out as given under. It is first proposed to evaluate the residual strength of all structural elements affected due to fire. Replace those elements alone with members of equivalent strength. The structural assessment made thereafter is considered acceptable. The thermal analysis using FEM is considered cumbersome and tedious. Hence, it is proposed to train a BOPN neural net with training patterns obtained from more cases of fire attacks. A BOPN neural net, developed already, will be used for simulating the training patterns. The information pertaining to the residual strength of elements subjected to fire will be obtained from the trained neural network.

\section{LITERATURE}

During a fire attack, the temperature normally reach $1000^{\circ} \mathrm{C}$ and above in buildings leading to severe structural damages. When concrete gets heated due to fire, the propagation of temperature to deeper layers happens progressively but at a slower rate. Therefore, significant temperature gradients are produced between the concrete surface and core inducing additional damage to concrete. The rate at which water gets evaporated from the heated concrete depends on the energy that binds the water with solid particles in concrete. Thus, free water evaporates first followed by capillary and physically bound water. The removal of water that is chemically bound with cement hydrates is the last to be initiated. Due to fire exposure the various changes that take place in concrete alters the physical, thermal and mechanical properties of concrete.

During heating, ettringite decomposition first takes place even before temperatures reach $100^{\circ} \mathrm{C}$. C-S-H gel decomposition is progressive and takes place from beginning of material heating. Structure of cement paste is partially damaged due to dehydration at a temperature of $105^{\circ} \mathrm{C}$; which is standard temperature for drying of materials. At about $500-550^{\circ} \mathrm{C}$, portlandite (calcium carbonate) rapidly drops as it decomposes to calcium oxide and water. Calcium oxide produced in this reaction makes the elements made of Portland cement practically redundant after cooling. Dehydration of C-S-H gel reduces volume which in turn increases porosity of the matrix. Moreover, during heating cement paste experiences a slight expansion up to $200^{\circ} \mathrm{C}$ although intense shrinkage begins as soon as this temperature is exceeded. This contributes to the porosity in cement paste.

The fire response of reinforced concrete members is influenced by characteristics of constituent materialsconcrete and reinforcing steel. The behaviour of concrete member exposed to fire depends on thermal, mechanical and deformation properties of concrete which substantially change within the temperature range associated with building fires. Thermal properties determine the extent of heat transfer to structural member. Mechanical properties determine the extent of strength loss and stiffness deterioration of the member, while, deformation in conjunction with mechanical properties determines the extent of deformations and strains in structural member. The mechanical properties are strongly affected by chemical bonds and cohesive forces between sheets of C-S-H gel. It is assumed that $50 \%$ of cement paste strength comes from cohesive forces. Thus, evaporation of water between $\mathrm{C}-\mathrm{S}-\mathrm{H}$ gel sheets strongly affects mechanical properties.

Since the temperature in excess of $200^{\circ} \mathrm{C}$ turns steel reinforcement brittle, it needs to be protected against heat. Concrete and steel exhibits similar thermal expansion coefficients up to $400^{\circ} \mathrm{C}$. However, higher temperatures result in significant expansion of steel compared to concrete. If temperature of the order of $700^{\circ} \mathrm{C}$ is attained, load carrying capacity of reinforcement gets reduced by $20 \%$ of its designed strength.

In design codes of RCC, the temperature variations across the depth of concrete cannot be considered to offer insulation effect to the structural steel reinforcement. Most of the studies in the past have been conducted with respect to certain predetermined heating regimes which might not be a representative of heating in real fire accident, that is, temperature-time curve used in fire tests; slow heating leading to reduced internal temperature gradients; using other temperature-time relationships appropriate only for specific applications.

One of the important aspects to be considered during a fire attack is spalling. Spalling is defined as breaking up of layers of concrete from surface when exposed to high and rapidly increasing temperatures. Spalling exposes deeper layers of concrete to fire temperatures thereby increasing the rate of transmission of heat to inner layers, including reinforcement. When reinforcement is exposed to fire, the temperatures in reinforcement rise at very high rate. This leads to faster deterioration in the strength of structural member. The loss of strength in reinforcement combined with that of concrete due to spalling significantly decreases the fire resistance of reinforced concrete structural member. Another impact is that due to reduction of cross-section of concrete available to support imposed loading, the stresses on remaining concrete members increase. 


\section{METHOD OF STUDY}

In the present study, a column member of dimensions $500 \mathrm{~mm} \times 300 \mathrm{~mm}$ is considered to be subjected to fire on one of its larger faces. A sample square portion of $500 \mathrm{~mm} \times 500 \mathrm{~mm}$ to a depth of $150 \mathrm{~mm}$ is considered for this purpose. Within this area, the central portion of $200 \mathrm{~mm} \times 200 \mathrm{~mm}$ is subjected to an increased temperature of $1000^{\circ} \mathrm{C}$ on the exterior face for a period of two hours. For the purpose of study, the area is divided into nine parts such that the central portion is of dimensions $200 \mathrm{~mm} \times 200 \mathrm{~mm}$.

The model consists of total number of nine solids. A temperature loading of $1000^{\circ} \mathrm{C}$ is applied on the external face of the exterior central solid. The default initial temperature of all other faces of the model other than the temperature exposed portion is taken as $27^{\circ} \mathrm{C}$. The temperature variation across the thickness is studied considering the variation of thermal conductivity with respect to temperature and porosity. The variation of thermal conductivity with temperature $(\theta)$ is computed as per the equation specified in Euro code 2.As per the code, the upper limit of thermal conductivity $\left(\lambda_{c}\right)$ of normal weight concrete may be determined from the following equation:

\section{$\lambda_{\mathrm{c}}=2-0.2451(\theta / 100)+0.0107(\theta / 100)^{2} \quad \mathrm{~W} / \mathrm{m}^{0} \mathrm{C}$ for $20^{\circ} \mathrm{C} \leq \theta \leq 1200^{\circ} \mathrm{C}$}

The variation of porosity with respect to temperature is calculated as per the following formula:

$$
\begin{array}{cc}
P=0.0131 \times T+5.6929 & T \leq 500^{\circ} \mathrm{C} \\
P=1.3978 \times \text { e0.0037 } \times T & T \geq 500^{\circ} \mathrm{C}
\end{array}
$$

The porosity is assumed to be inversely proportional to the thermal conductivity. Using the above equations, the increase in porosity with respect to temperature is calculated. The thermal conductivity values calculated as per the equation are reduced in proportion to that of porosity increase and then given as input in properties field. Other than the thermal conductivity, specific heat and density are specified and the values are as follows:

\section{Specific heat $\left(\mathbf{C}_{\mathrm{p}}\right): \mathbf{8 8 0} \mathrm{J} / \mathrm{kg}^{\circ} \mathrm{C}$}

Density ( $\rho): 2400 \mathbf{~ k g} / \mathrm{m}^{3}$

For the purpose of finite element analysis the model is suitably meshed so that the edges of the solid along the depth are divided into eight elements and then meshed. Transient thermal analysis, i.e. time dependent thermal analysis is carried-out on the model. The temperature is applied in time steps of 10minutes each for twelve times. Thus, the analysis of model exposed to a temperature of $1000^{\circ} \mathrm{C}$ for a period of 2 hours is carried- out to obtain the temperature distribution throughout the portion of the solid under interest. Having completed the thermal analysis, with the known outputs of temperature readings as thermal loads at different locations, the structural analysis is taken-up. From this analysis the magnitudes of thermal strains and thermal stresses at different locations are evaluated. The grade of concrete considered is M35 and the material is considered to be linearly elastic and isotropic.

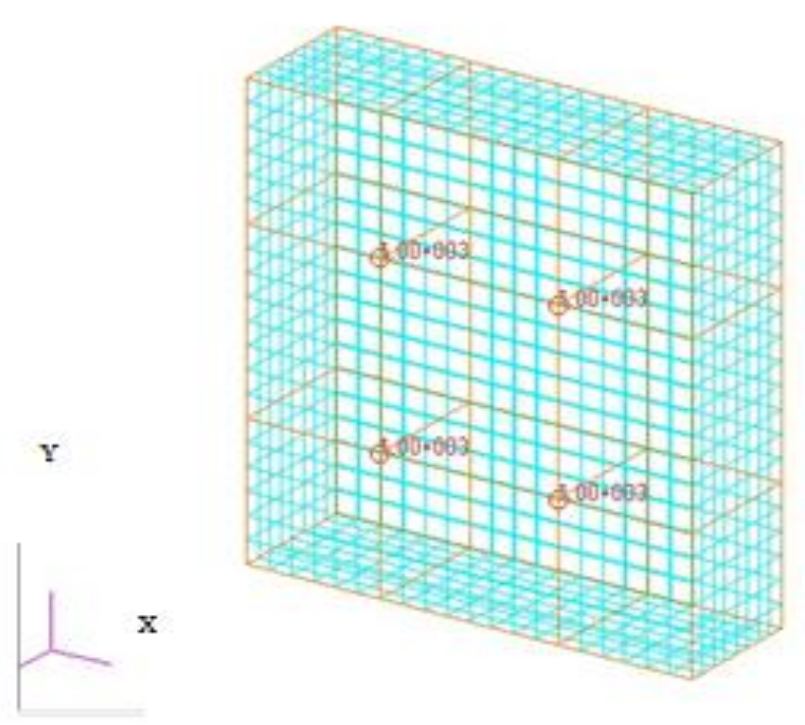

Fig- 1: Finite element model

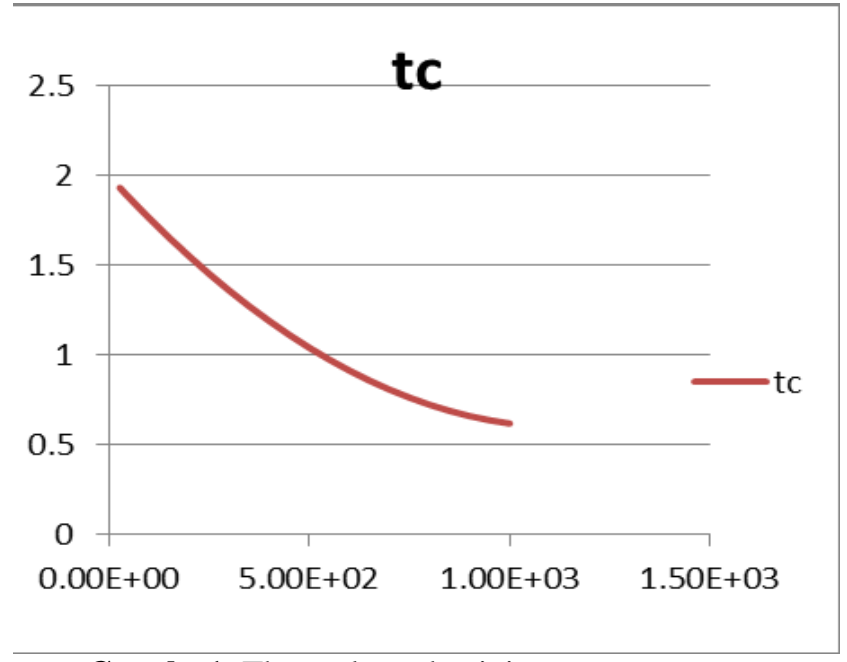

Graph -1: Thermal conductivity vs. temperature

In the properties field of the FE analysis, elastic modulus, Poisson's ratio, coefficient of thermal expansion and reference temperature are specified. Following are list of values specified:

For M35 grade concrete:

\section{Elastic Modulus: $5000 \sqrt{\mathbf{f}_{\text {ck }}}=2.958 \mathrm{E10} \mathrm{N} / \mathrm{m}^{2}$ Poisons Ratio: 0.15 \\ Coefficient of thermal expansion: $14.5 \mathrm{E}-6 /{ }^{\circ} \mathrm{C}$ Reference temperature: $27^{\circ} \mathrm{C}$}

The above given values of properties are assigned to the whole of the solid. The top and bottom faces of the model are considered to be fixed and the obtained temperatures are given as thermal loads on all faces of the model. Linear static analysis is carried out and thermal stresses and strains are obtained. 


\section{NEURAL COMPUTING}

Neural computing paradigm that is inspired by the functioning of human brain has attracted researchers from almost all disciplines of structural engineering for computerisation of ill conditioned tasks. This computing technology called neural computing, attempts at simulating the functioning of human brain very approximately in a mathematical form. The biochemistry of the neurons is not yet fully understood. Figure. 2 shows the structure of a biological neuron. The main parts of a biological neuron are the cell body, the axon and the dendrite. The dendrite is responsible for carrying signals from the cell body to the other neurons. The axon on the other hand carries signals from the cell body to other neurons. The dendrite and axon meet at a point called synapses.

\subsection{Artificial Neuron}

The artificial neuron is an approximately simulated model of the biological neuron. The artificial neuron can carry out only a very simple mathematical function and/or can compare two values. Figure. 3 shows the essential parts of an artificial neuron. An artificial neuron has a typical function associated to it, which is often called as threshold function or squashing function. A typical artificial neuron gets an input either from other neurons or directly from the environment (i.e. input nodes). The paths connecting the input nodes to the neurons and connections between the various neurons are associated with a certain variable weight, which represents a multiplying factor for the incoming signal representing the synaptic strength of the connections. These weights are initially set to some random values and are later adjusted in the process of training the net. The artificial neuron then sums this input which is actually a weighted sum of all the input signals. The input so obtained is used to calculate a node value according to the squashing function of the neuron. This node value is compared with the threshold value of the neuron and if the node value is higher, then the neuron goes to the "higher state" (excitation state) and a signal is passed on to the next layer of neurons. The three common types of non-linear nodal functions generally used are shown Figure.4.

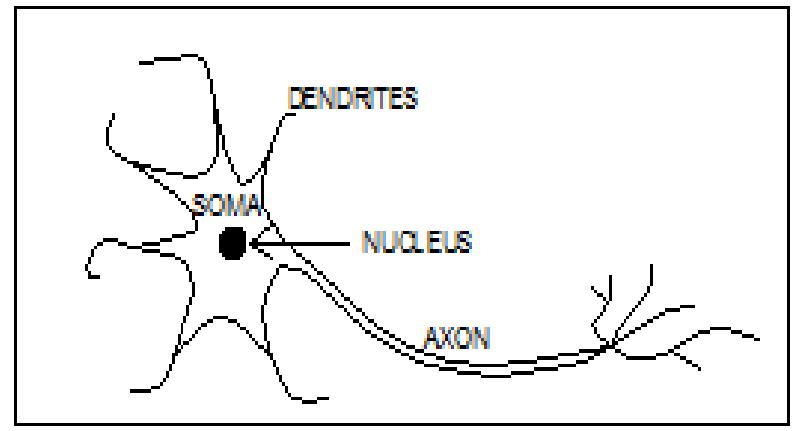

Fig-2: Biological neuron

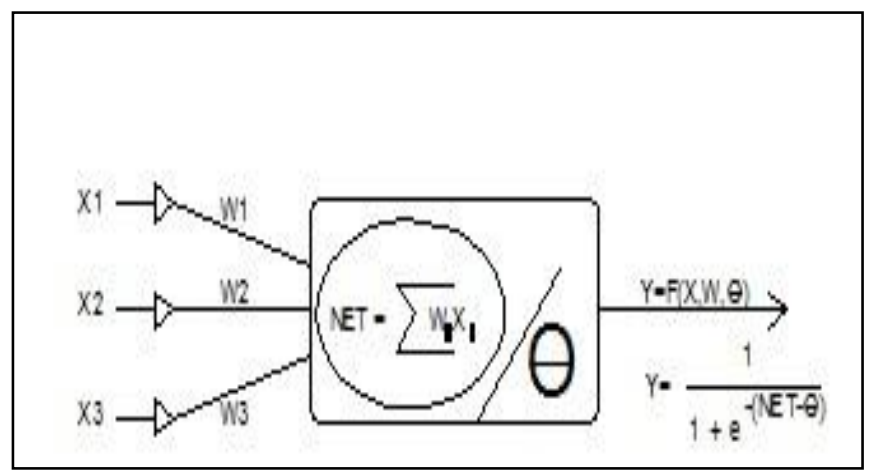

Fig- 3: Artificial neuron

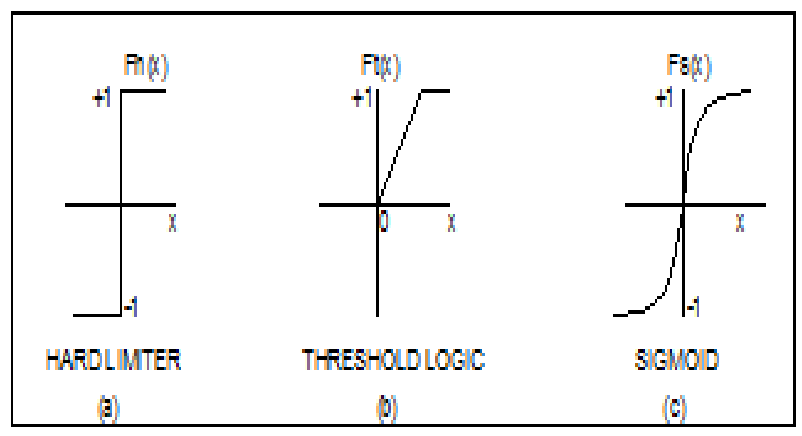

Fig- 4: Nodal functions

\section{SPECIMEN CALCULATIONS}

The stresses (in $\mathrm{N} / \mathrm{mm}^{2}$ ) for the four corner elements of the exterior central solid at the end of two hours of fire exposure are given in Table1. The corresponding strains for the four corner elements of the central solid are given in Table 2.The strains at the nodes on the exterior surface at the end of two hours are given in Table 3 . In the table positive values indicate tension and negative values indicate compression.

Table -1: Thermal stresses in corner elements of the exterior central solid at the end of two hours

\begin{tabular}{|l|l|l|l|l|l|l|}
\hline $\begin{array}{l}\text { Entity } \\
\text { ID }\end{array}$ & $\begin{array}{l}\mathbf{X X} \\
\left(\mathbf{N} / \mathbf{m m}^{2}\right)\end{array}$ & $\begin{array}{l}\mathbf{Y Y} \\
\left(\mathbf{N} / \mathbf{m m}^{2}\right)\end{array}$ & $\begin{array}{l}\mathbf{Z Z} \\
\left(\mathbf{N} / \mathbf{m m}^{2}\right)\end{array}$ & $\begin{array}{l}\mathbf{X Y} \\
\left(\mathbf{N} / \mathbf{m m}^{2}\right)\end{array}$ & $\begin{array}{l}\mathbf{Y Z} \\
\left(\mathbf{N} / \mathbf{m m}^{2}\right)\end{array}$ & $\begin{array}{l}\mathbf{Z X} \\
\left(\mathbf{N} / \mathbf{m m}^{2}\right)\end{array}$ \\
\hline 1793 & -160.53 & -224.28 & -0.92 & -55.21 & -5.51 & -7.27 \\
\hline 1800 & -160.53 & -224.28 & -0.92 & 55.21 & -5.51 & 7.27 \\
\hline 1849 & -160.53 & -224.28 & -0.92 & 55.21 & 5.51 & -7.27 \\
\hline 1856 & -160.53 & -224.28 & -0.92 & -55.21 & 5.51 & 7.27 \\
\hline
\end{tabular}


Table -2: Thermal strains in corner elements of the exterior central solid at the end of two hours

\begin{tabular}{|l|l|l|l|l|l|l|}
\hline $\begin{array}{l}\text { Entity } \\
\text { ID }\end{array}$ & $\mathbf{X X}$ & $\mathbf{Y Y}$ & $\mathbf{Z Z}$ & $\mathbf{X Y}$ & $\mathbf{Y Z}$ & $\mathbf{Z X}$ \\
\hline 1793 & 0.006044 & 0.003565 & 0.012249 & -0.002146 & -0.000214 & -0.000283 \\
\hline 1800 & 0.006044 & 0.003565 & 0.012249 & 0.002146 & -0.000214 & 0.000283 \\
\hline 1849 & 0.006044 & 0.003565 & 0.012249 & 0.002146 & 0.000214 & -0.000283 \\
\hline 1856 & 0.006044 & 0.003565 & 0.012249 & -0.002146 & 0.000214 & 0.000283 \\
\hline
\end{tabular}

Table -3: Thermal strains at the nodes on the exterior surface at the end of two hours

\begin{tabular}{|l|l|l|l|l|l|l|}
\hline Entity ID & $\mathbf{X X}$ & $\mathbf{Y}$ & $\mathbf{Z Z}$ & $\mathbf{X Y}$ & $\mathbf{Y Z}$ & $\mathbf{Z X}$ \\
\hline 393 & 0.000228 & -0.004066 & -0.000025 & -0.001560 & -0.000272 & -0.000000 \\
\hline 399 & 0.000003 & -0.003404 & 0.000126 & -0.001880 & 0.000570 & 0.000000 \\
\hline 435 & 0.000385 & 0.000989 & 0.000426 & -0.000689 & -0.000301 & -0.000036 \\
\hline 954 & 0.000003 & -0.003404 & 0.000126 & 0.001880 & 0.000570 & -0.000000 \\
\hline 1032 & 0.000203 & 0.000064 & 0.000418 & 0.000099 & 0.000044 & 0.000033 \\
\hline 1407 & 0.000228 & -0.004066 & -0.000025 & 0.001560 & -0.000272 & -0.000000 \\
\hline 2010 & 0.000385 & 0.000989 & 0.000426 & 0.000689 & 0.000301 & -0.000036 \\
\hline 3312 & 0.000385 & 0.000989 & 0.000426 & -0.000689 & 0.000301 & 0.000036 \\
\hline 3336 & 0.000151 & -0.000202 & 0.000302 & -0.000039 & 0.000041 & -0.000009 \\
\hline 3747 & 0.000228 & -0.004066 & -0.000025 & 0.001560 & 0.000272 & -0.000000 \\
\hline 3785 & 0.000664 & 0.000322 & 0.000744 & -0.000000 & -0.000163 & 0.000000 \\
\hline 4761 & 0.000228 & -0.004066 & -0.000025 & -0.001560 & 0.000272 & 0.000000 \\
\hline
\end{tabular}

\section{RESULTS AND DISCUSSIONS}

The gradient of temperature variation is very flat and irregular in concrete unlike for metals, as concrete is a heterogeneous material. In the study, the variation of thermal conductivity with changes in temperature values has been considered. Similarly, the variation of thermal conductivity due to porosity has also been taken into consideration based on the available information. Magnitudes of temperature at different locations in concrete have been recorded at every ten minute intervals for two hours. Based on the FEM output, it is observed that the heat does not percolate till the core of concrete until one hour twenty minutes from the beginning of fire attack. From then on variation of temperature inside concrete core is found to increase rapidly.

The variation in compressive strength of concrete with temperature for each grade of concrete as reported in Euro code is presented in Table 4 . The information is found very useful for determining the residual strength of concrete. The magnitude of temperature in a few elements located in the central portion with corresponding compressive strengths after two hours of fire exposure is presented in Table 5. With these temperature readings as thermal inputs, the stresses and strains in the concrete are evaluated next using the same Finite Element Package. The thermal stresses calculated thus are acting in addition to the stresses caused due to the structural loads. The resultant stresses and strains obtained as described above shall not exceed the permissible strength of concrete for the sustenance of structure.

The information obtained from the thermal analysis followed by the structural analysis was found very encouraging since no expensive and tedious experimental work is involved in the whole process. This has encouraged in generating a large amount of data of such information with varying parameters of temperature, duration of fire attack and concrete properties. This information is proposed to be used later as set of training patterns to train a BOPN based neural net paradigm. The trained neural net would readily furnish the information regarding temperature 
propagation in a concrete element with arbitrary parameters. Such information may be used for working out the sizes of equivalent structural elements in the distressed structure. The revised structural configuration with the distressed $\mathrm{RC}$ element replaced by equivalent elements should facilitate the process of structural evaluation.

Table -4: Decrease in compressive strength with

\begin{tabular}{|l|l|}
\hline $\begin{array}{l}\text { Concrete } \\
\text { Temperature }\left({ }^{\mathbf{}} \mathbf{C}\right)\end{array}$ & $\mathbf{f}_{\mathbf{c} \mathbf{}} / \mathbf{f}_{\mathbf{c k}}$ \\
\hline 20 & 1.00 \\
\hline 100 & 1.00 \\
\hline 200 & 0.95 \\
\hline 300 & 0.85 \\
\hline 400 & 0.75 \\
\hline 500 & 0.60 \\
\hline 600 & 0.45 \\
\hline 700 & 0.30 \\
\hline 800 & 0.15 \\
\hline 900 & 0.08 \\
\hline 1000 & 0.04 \\
\hline 1100 & 0.01 \\
\hline 1200 & 0.00 \\
\hline
\end{tabular}

Table -5: Decrease in compressive strength of central

\begin{tabular}{|l|l|l|}
\hline $\begin{array}{l}\text { Element } \\
\text { ID }\end{array}$ & $\begin{array}{l}\text { Temperature } \\
\left({ }^{\mathbf{0}} \mathbf{C}\right)\end{array}$ & $\begin{array}{l}\text { Compressive } \\
\text { Strength } \\
\left(\mathbf{N} / \mathbf{m m}^{\mathbf{2}}\right)\end{array}$ \\
\hline 1361 & 121.17 & 34.63 \\
\hline 1425 & 131.99 & 34.44 \\
\hline 1489 & 154.72 & 34.04 \\
\hline 1553 & 191.90 & 33.39 \\
\hline 1617 & 248.46 & 31.55 \\
\hline 1681 & 334.50 & 28.54 \\
\hline 1745 & 473.27 & 22.40 \\
\hline 1809 & 779.98 & 6.30 \\
\hline
\end{tabular}

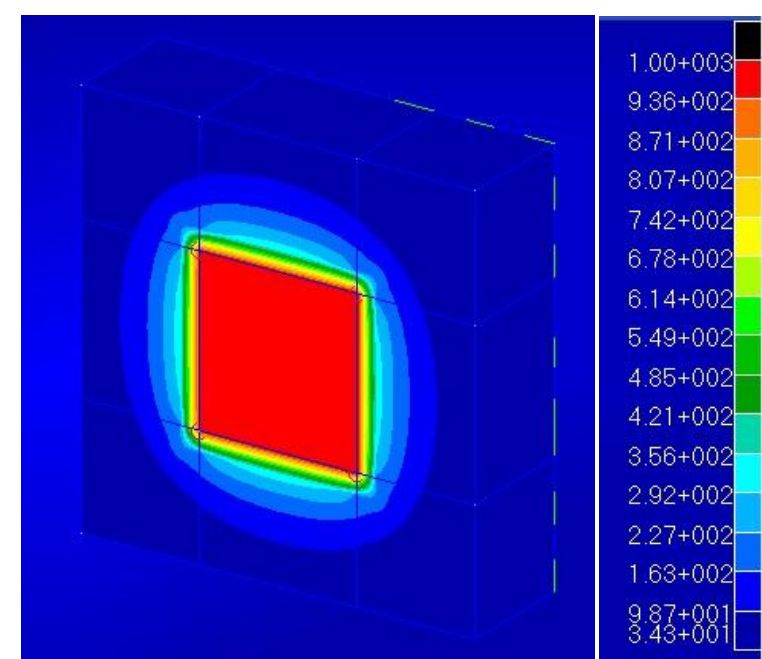

Fig -5: Distribution of temperature throughout the solid
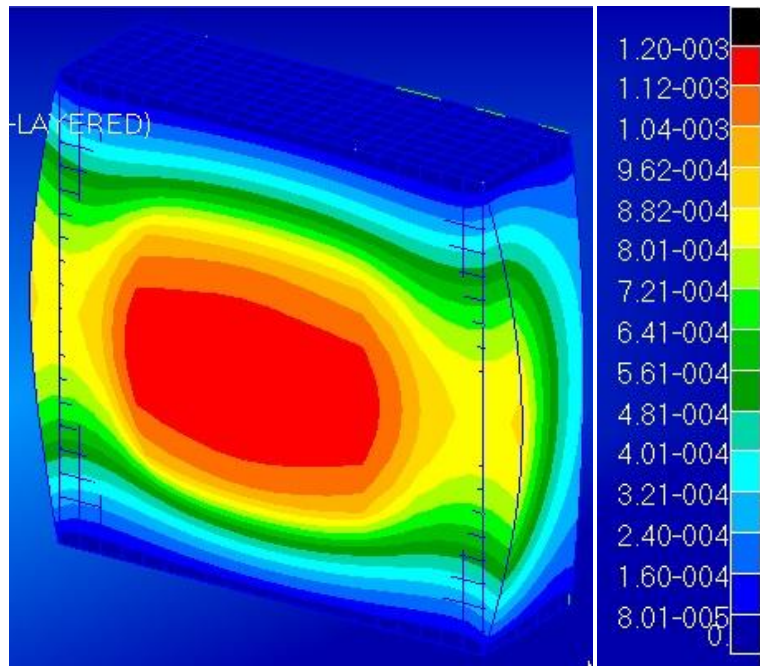

Fig -6: Displacement profile for two hours duration

\section{SCOPE FOR FUTURE}

In the present study, the distress in concrete alone is investigated. The effect of temperature on the strength of steel, the bond between steel and concrete are to be explored. Consideration of geometric and material nonlinearity would make the study more complete.

\section{REFERENCES}

[1]. D. Gawin, C.E. Majorana, and B.A. Schrefler, "Numerical analysis of hygro-thermal behaviour and damage of concrete at high temperature" Mechanics of Cohesive-Frictional Materials, 37-74 (1999).

[2]. Venkatesh Kodur, "Properties of Concrete at Elevated Temperatures"'ISRN Civil Engineering, Volume 2014 (2014), Article ID 468510.

[3]. Belkacem Toumi and Musa Resheidat "Influence of High Temperatures on Surface Cracking of Concrete Studied by Image Scanning Technique” Jordan Journal of Civil Engineering, Volume 4, No. 2, 2010.

[4]. A. Fletcher Ian, Stephen Welch, L. Torero Jose, O. Carvel Richard and Asif Usmani "Behaviour of Concrete Structures in Fire",

[5]. EN 1992-1-2 (2004) (English): Eurocode 2: Design of concrete structures - Part 1-2: General rules - Structural fire design [Authority: The European Union per Regulation 305/2011, Directive 98/34/EC, Directive 2004/18/EC].

\section{BIOGRAPHIES}

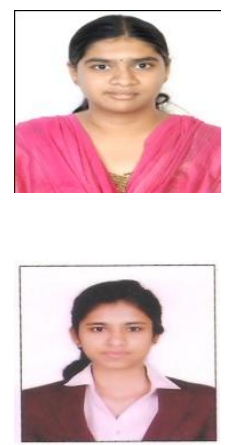

D.Reshmasri is presently pursuing her M.E(Structural Engineering) in department of Civil Engineering at University college of Engg, Osmania University.

Dheera Lessa is presently pursuing her B.E (Civil Engineering) in department of Civil Engineering at University college of Engg, Osmania University. 